\title{
Adaptação e adversidade no cotidiano de trabalhadores sertanejos em canções de Luiz Gonzaga
}

Geovanna Santana de Souza Turri. Universidade Federal de Sergipe

André Faro. Universidade Federal de Sergipe

Marley Rosana Melo de Araújo. Universidade Federal de Sergipe

\section{Resumo}

Luiz Gonzaga, em algumas de suas canções, canta a história de vida daqueles que partem em busca de um trabalho melhor, numa tentativa de amenizar a precariedade da vida. Em vista disso, esta pesquisa buscou identificar características da realidade de vida sertaneja, suas relações com o trabalho e mecanismos adaptativos narrados nas canções de Luiz Gonzaga. O corpus textual foi composto por 36 canções e as letras foram catalogadas e analisadas com o auxílio do programa IRAMUTEQ, que gerou quatro classes léxicas: Caracterização do trabalho sertanejo; Migração; Desejo de retorno à terra e Proteção divina. Percebeu-se que ele cantava os sertanejos e as estratégias de enfrentamento que eles desenvolvem na tentativa de se adaptarem positivamente às adversidades. Finalmente, acredita-se que conhecer o conteúdo das canções de Luiz Gonzaga ajudou a compreender representações do contexto sertanejo em memórias e elementos cotidianos da vida desse povo.

Palavras-chave: enfrentamento; adaptação; sertão; trabalho; canção.

\begin{abstract}
Adaptation and adversity in daily life of hinterland workers at Luiz Gonzaga's songs. Luiz Gonzaga sang the life's history of those who leave his lands looking for a better work in order to try reducing their life's precarity. This research aimed to investigate characteristics of Brazilian hinterlands living reality, their relationships with work, and adaptive mechanisms from Luiz Gonzaga's songs. The textual corpus was composed of 36 songs and the song lyrics were fully transcribed and analyzed through IRAMUTEQ software. It was generated four lexical classes: Characterization of hinterlands man's work; Migrations; Desire to return, and God's protection. We observed that Luiz Gonzaga sang about those people and strategies that they develop facing adversities to achieve a positive level of adaptation. At the end, we concluded that knowing this artist and his song's help to understand representations of that social context, which also include memories and other elements that ease to know ordinary experiences related to the hinterlands man's life.
\end{abstract}

Keywords: coping; adaptation; hinterlands; work; song.

\section{Resumen}

Adaptación y adversidad en la vida diaria de los trabajadores del Sertão brasileño en las canciones de Luiz Gonzaga. Luiz Gonzaga canta la historia de vida de los que salen en busca de un trabajo mejor con el intento de aliviar la precariedad de su vida. Esta investigación buscó identificar las características de la realidad vivida por la población del Sertão brasileño, su relación con el trabajo y mecanismos de adaptación, de acuerdo con las canciones de Luiz Gonzaga. El corpus fue compuesto de 36 canciones y todas las letras fueron analizadas con el programa IRAMUTEQ. Cuatro clases léxicas fueron obtenidas: Caracterización del trabajo en el Sertão; Migración; El deseo de regresar a casa; y Protección Divina. Los resultados mostraron que Gonzaga cantaba estrategias de supervivencia desarrolladas en un intento de adaptarse positivamente a la adversidad. Por fin, conocer su producción y contenido de sus canciones ayudó a comprender representaciones del Sertão presentes en recuerdos y elementos cotidianos a cerca de la vida de su pueblo.

Palabras clave: afrontamiento; adaptación; sertão; trabajo; canción. 
O nordeste brasileiro, dentre as cinco regiões do país, é peculiar. Ele tem como características uma série de fatores específicos, dentre os quais se destacam a cultura, a geografia, o clima, hidrografia e vegetação, além do indesejado atraso em alguns quesitos do desenvolvimento socioeconômico (J. R. Silva \& Jesus, 2012). Devido a seu clima seco, à miséria do povo do sertão e sua migração, fomentou-se uma imagem perniciosa do Nordeste enquanto região inferior às demais do país (R. A. Santos, 2013). Por outro lado, a seca existente na região foi utilizada, por muitos, como elemento criativo para relatar fatores funcionais e não funcionais da região e de seu povo.

Os problemas encerrados nos fatores não funcionais, a exemplo das condições precárias de sobrevivência para pessoas e animais durante o período de seca, disseminaram a imagem de um Nordeste miserável, que findou retratado em obras literárias e canções. Por vezes, tais formas de expressão cultural tentaram chamar atenção para a região, de forma que refletisse um pedido de ajuda para amenizar a situação crítica da localidade ( $R$. A. Santos, 2013; Sousa, 2017). Foram esses problemas que acometem a região do sertão nordestino que ficaram marcados nas letras das canções de Luiz Gonzaga. Ele retratou o sertão, a narrativa da terra e de seus habitantes, sua religiosidade e a busca por uma vida melhor.

Ao deixar o Nordeste na década de 1940, Luiz Gonzaga foi para o Rio de Janeiro e passou a fazer apresentações de músicas do forró pé-de-serra. Nessa época predominavam nas rádios estilos musicais como samba, chorinho e valsa. Porém, o mercado fonográfico pedia um estilo novo, diferente, capaz de atrair velhos e novos consumidores, motivando o rei do baião a cantar canções e lançar ritmos nordestinos no Sudeste (Sousa, 2017). Luiz Gonzaga então combinou elementos da música que aprendeu em Pernambuco e elementos da música tocada na época no Rio de Janeiro, fazendo uma conexão entre duas regiões bem distintas do Brasil (C. O. Santos, 2012). Foi assim que o baião virou sucesso no Brasil, causando uma reviravolta entre as décadas de 1940 e 1950 na Música Popular Brasileira (Cordeiro, 2008). Nessas décadas o Nordeste era ainda mais carente, marcado pela seca, o que é representado nas canções de Luiz Gonzaga, sendo considerada a época mais produtiva em relação a seu marketing e sucesso nacional (Costa, 2012).

Homem simples e do campo, Gonzaga presenciou dificuldades e alegrias de seu povo, e por isso foi considerado apto a informar - por intermédio de suas canções - como os nordestinos, em especial os sertanejos, representavam a realidade na qual viviam, configurando um objeto de estudo incomum, todavia altamente promissor em sua representatividade (I. G. V. Rocha, 2013). Suas canções, sejam elas autorais ou apenas interpretadas, apresentam traços ligados à cultura sertaneja e nordestina, trazendo um arcabouço identitário que descreve o que é ser habitante dessa região (Coelho \& Trentin, 2014). Além da identidade nordestina (Fernandes, 2008), encontra-se na literatura trabalhos que analisaram as canções de Luiz Gonzaga para o entendimento do sagrado (Gama, 2012), das práticas alimentares (Sobral, 2015), do estereótipo do "cabra macho" nordestino (Brilhante, Silva, Vieira, Barros, \& Catrib, 2017; Trotta, 2012), dentre outros temas voltados para o cotidiano do nordestino.

Como outras obras de arte, uma letra de música não reflete de forma automática uma dada realidade. Logo, é necessário entender o contexto no qual a canção foi composta (I. G. V. Rocha, 2013). Luiz Gonzaga foi hábil em musicar a imagem do retirante nordestino, que foge da terra seca e exaurida pelo sol, muitas vezes deixando a família e partindo para o sul e sudeste na busca ilusória de melhores dias, deparando-se com trabalhos precários (Coelho \& Trentin, 2014; Moraes, 2009). Em vista de características como essas, para muitos nordestinos as canções de Luiz Gonzaga passavam uma sensação de aconchego e amenizavam a saudade do sertanejo ausente de suas origens (Costa, 2012).

Os temas musicados por Luiz Gonzaga podem ser compreendidos como problemas do homem sertanejo, tendo sido abordados muitas vezes de forma lúdica, especialmente quando falavam dos detalhes do dia-a-dia. Segundo a análise temática realizada por J. F. Santos (2004), na obra do cantor podem ser encontrados os seguintes temas centrais: a) crueldade da seca e migração; b) a proteção divina; c) a relação homem-natureza e; d) o desejo de retorno. Isso reforça que seu cancioneiro tem muito mais a contribuir do que somente a garantia de entretenimento e divertimento de seus ouvintes. Torna-se, portanto, um referencial interessante para a análise de como o sertanejo lida/lidava com as adversidades cotidianas então ilustradas na obra musical desse cantor.

É possível entender que canções retratam uma dada realidade social, visto que revelam mais do que palavras, de forma a construir sentido em torno do objeto e contexto cantados (I. G. V. Rocha, 2013). Assim, a linguagem musical desperta valores sociais, crenças e uma visão de mundo que vai além do imaginário, permeando o mundo real (Cordeiro, 2008). Como apontado por Freire (2010), o estilo e a linguagem musical 
carregam sentidos variados, que podem ser interpretados de acordo com a experiência de vida de cada indivíduo e/ou de cada grupo, o que contribui para a formação da identidade. Consequentemente, canções podem ser um meio para o estudo de aspectos psicológicos individuais e coletivos.

Em resumo, tendo em vista que Luiz Gonzaga é um notório representante dos nordestinos e canta aspectos psicossociais em suas canções, este trabalho teve como proposta geral conhecer como os trabalhadores sertanejos lidavam com os desafios de vida. Para tanto, desenvolveu-se uma análise psicológica dos conteúdos presentes nas canções de Gonzaga. Dentre os contextos retratados nas canções que foram elementos desta investigação, distingue-se a atividade de trabalho e seus aspectos caracterizadores. Sabe-se que o trabalho tem um papel importante na estruturação da identidade do indivíduo, além de ser um elemento fundamental na transformação das relações sociais. Vale destacar que nem toda atividade laboral transcorre dentro de organizações ou sob marcos de segurança, a exemplo do trabalho no ambiente rural, que é, geralmente, caracterizado pela precarização e desqualificação do trabalhador, assumindo contornos de trabalho informal, sobrecarga e baixa remuneração (Pereira \& Ribeiro, 2014).

Nas zonas rurais, o trabalho ainda hoje possui características ilustradas nas letras das canções de Luiz Gonzaga, predominando a mão de obra pesada em plantações. No entanto, quando ocorre o período de seca, esses trabalhadores acabam tendo que buscar outras maneiras para prover seu próprio sustento e de suas famílias, já que sem chuva, a colheita é prejudicada (Baptista, 2013).

No Nordeste, os fluxos migratórios se caracterizaram pela migração entre regiões do Brasil e pelo grupo de trabalhadores rurais temporários que fazem o deslocamento durante o período das safras, rodando pelo país de acordo com o calendário agrícola (Coelho \& Trentin, 2014). Podem ser citados como principais agentes migratórios: (a) a motivação por uma vida melhor, principalmente para aqueles que migram das regiões mais pobres do país, ou seja, do sertão que sofre com as secas (R. A. Santos, 2013); (b) fatores como a crise econômica, o aumento do desemprego e (c) a precarização do trabalho, que contribuem para a precariedade da vida e para a migração compulsória dos sertanejos pobres (Pereira \& Ribeiro, 2014).

Tanto a longa estiagem no sertão nordestino, quanto à saída forçada para outra região, constituem-se fatores adversos ainda comuns à vida de muitos sertanejos, uma vez que não é fácil abandonar seu lar, sua terra e embarcar rumo a uma região diferente, com cultura diferente, sozinho e, muitas vezes, desamparado. Tais fatores podem exercer uma forte carga de sofrimento e demandar sofisticadas habilidades adaptativas em nível psicológico, o que, quando não suficiente, facilitam o adoecimento físico e psicológico (Sousa Camurça, Alencar, Cidade, \& Ximenes, 2016).

Frente às dificuldades encontradas ao longo da vida, é importante que as pessoas aprendam a desenvolver potenciais positivos para se adaptar, isto é, manejar o mais saudavelmente possível os desafios que aparecem rotineiramente. $O$ processo de adaptação pode ser conceituado como o meio pelo qual o indivíduo administra suas relações com os outros, com o ambiente e consigo mesmo (Faro \& Pereira, 2013). No processo adaptativo, o indivíduo busca diferenciar situações positivas das negativas e reagir a elas, de forma a aprender a guiar de modo mais saudável a própria vida (Folkman, 2011). Assim, levando-se em consideração que o sofrimento está presente na vida de todo ser humano, e que em alguns momentos isto pode levar a danos psicológicos, é possível analisar fatores situacionais e/ou ambientais que interferem no bem-estar dos indivíduos. Sendo então o trabalho uma atividade que consome um considerável tempo de vida, são importantes as investigações que busquem conhecer as principais adversidades e os mecanismos adaptativos desenvolvidos nesse contexto (Bendassolli \& Gondim, 2013).

Dado o exposto, este trabalho objetivou apreender as características da realidade de vida sertaneja e seus mecanismos de adaptação, obtidos sob a perspectiva do trabalho sertanejo narrado nas canções de Luiz Gonzaga. A seleção de canções voltadas aos temas "trabalho e trabalhador sertanejo/nordestino" serviram como ponto de partida da análise. Esse recorte permitiu a constituição de um panorama para o conhecimento das principais características do trabalhador sertanejo, suas dificuldades, eventos estressores, fatores de risco, fatores de proteção e mecanismos de adaptação frente às dificuldades narradas. Logo, com base nessa proposta, as questões norteadoras deste trabalho foram:

a) Quais as principais dificuldades dos sertanejos segundo Luiz Gonzaga?

b) Como o trabalho do sertanejo é representado em suas canções?

c) Como o trabalhador sertanejo lida com dificuldades cotidianas encontradas em relação ao trabalho (ou sua falta) no sertão, de acordo com o repertório musical de Gonzaga? 


\section{Método}

\section{Fonte dos Dados e Procedimentos}

Dentre mais de 600 canções que compõem a obra interpretada por Luiz Gonzaga (U. M. Silva, 1997), obtiveram-se as letras de 531 delas em um site de acesso gratuito, cuja proposta é catalogar e disponibilizar sua musicografia (http://gonzagao.com/discografia-de-luiz-gonzaga/). A partir da catalogação dessas letras, realizou-se leitura flutuante de todas com o intuito de selecionar apenas aquelas que se inserissem nos critérios de inclusão, que consistiram em abordar conteúdos relacionados a 'trabalho', 'trabalhador nordestino', 'trabaio', 'trabaiador', 'roceiro' e 'vaqueiro'. A seleção amostral considerou a presença dessas palavras e também o conteúdo musical que contextualizava as canções no conjunto das palavras-chave. Optou-se por não incluir na amostra as canções que faziam alguma homenagem a determinada profissão, a exemplo do carteiro ou taxista, por não se tratar de uma condição mais fortemente associada à região Nordeste, isso em comparação a outras regiões do país. Com base das letras selecionadas, foi criado um corpus textual contendo 36 canções (aproximadamente 7\% do total inicialmente avaliado), o que constituiu, então, o objeto de análise desta pesquisa.

\section{Análise dos Dados}

As 36 canções selecionadas no site mencionado foram transpostas na íntegra para o Word e analisadas por meio do programa IRAMUTEQ (www.iramuteq.org), que permite fazer análises estatísticas sobre corpus textuais e sobre tabelas (Camargo \& Justo, 2013). Dentre as análises possíveis no programa, optou-se por utilizar neste estudo a Classificação Hierárquica Descendente (CHD) e o dendograma de classes (Camargo \& Justo, 2013). A CHD permite a análise de segmentos de textos que apresentam vocabulário semelhante entre si e vocabulário diferente de outros segmentos de texto, simultaneamente, calculando distâncias e proximidades a partir de testes do Qui-Quadrado (Camargo, 2005).

Como produto da análise, o IRAMUTEQ organiza as palavras em um dendograma, que representa a quantidade e composição léxica de classes a partir de um agrupamento de termos, do qual se obtém a frequência absoluta de cada um deles e o valor de Qui-Quadrado agregado. A partir da avaliação do dendograma, visualizou-se o conjunto de palavras agrupadas nas classes, sendo que as mais representativas são aquelas com valor de Qui-Quadrado mais elevado. Em cada uma das classes designou-se uma nomenclatura conceituando o conteúdo lexical obtido por meio da CHD, o que procurou representar o aspecto semântico passível de interpretação a partir da organização dos léxicos em classes.

\section{Resultados e discussão}

O IRAMUTEQ repartiu o corpus em 218 segmentos, quatro classes e uma média de 36 palavras por segmento. As classes obtidas através da CDH foram nomeadas da seguinte maneira: Características do trabalho sertanejo (28,9\% dos segmentos de texto); Migração (27,9\% dos segmentos de texto); Desejo de Retorno à terra (22, 9\% dos segmentos de texto); e Proteção Divina (20,1\% dos segmentos de texto) (Figura 1).

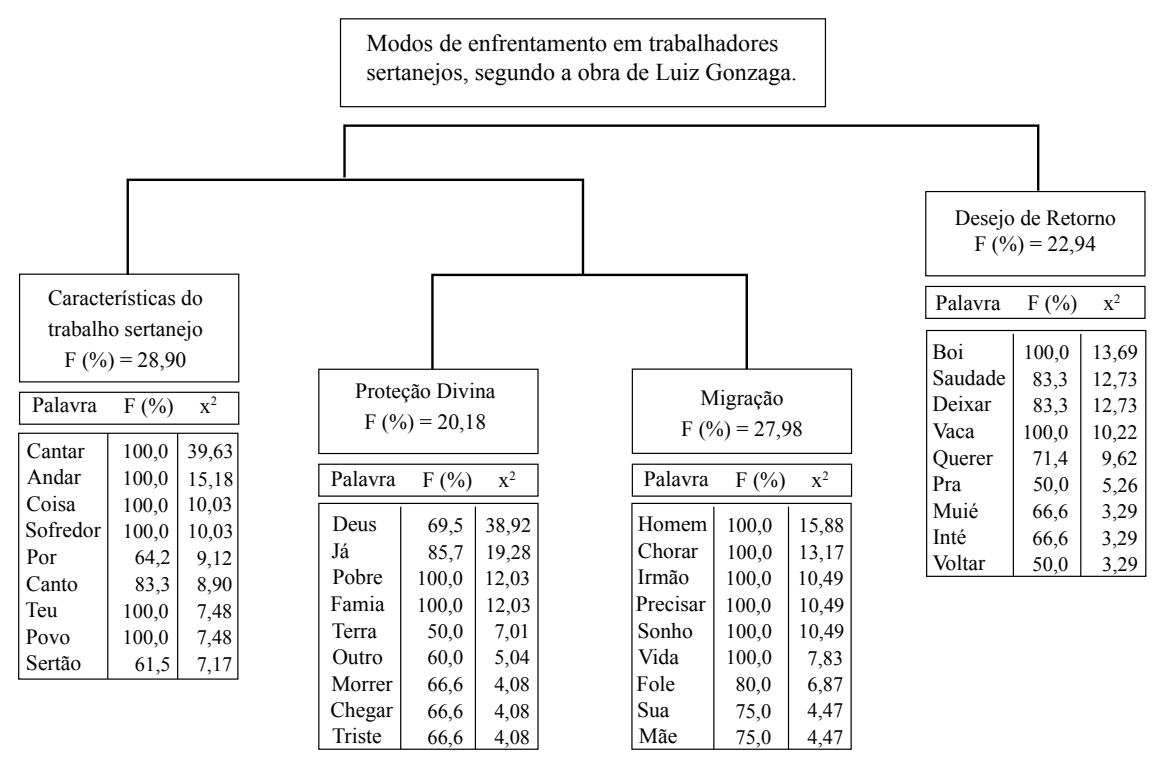

Figura 1. Dendograma de Classes. 


\section{Características do Trabalho Sertanejo (28,9\%)}

Observou-se que nesta classe o tema central se referiu às características do trabalho e do trabalhador sertanejo. Fartamente retratado na composição de Luiz Gonzaga, o trabalho rural é visto recorrentemente como fator de desgaste físico e emocional para muitos trabaIhadores, pois, muitas vezes, apresenta condições penosas e/ou perigosas de execução (duração da jornada, redução de horas de sono em função do início da jornada ocorrer antes da aurora, exposição às intempéries, ausência de EPIs, etc.). O trabalho no campo se destacou como um conjunto de desafios do dia a dia para os trabalhadores sertanejos. Os termos mais associados a esta classe foram: "cantar", "andar", "coisa", "sofredor", "por", "canto", "teu", "povo" e "sertão". Propõe-se a seguinte sentença, construída pelos pesquisadores à parte da análise da classe, para representar o conteúdo central que pode ser extraído do léxico então agrupado: "O povo do sertão é trabalhador e sofredor, mas não se abate com a miséria e andam pelo sertão em busca de trabalho, cantando para espantar os males que os cercam".

O ambiente rural é equivalente ao campo, abarcando todos os membros que vivem em uma coletividade rural, isto é, que trabalham na agricultura ou em outras atividades inseridas no campo (Albuquerque, 2002). Embora haja registros e pesquisas com a população rural, nota-se escassez de estudos que visem a conhecer aspectos psicológicos relacionados à saúde física e mental dos trabalhadores que vivem nessa região, em especial daqueles que vivem na região rural mais caracterizada por secas. Nesta classe se destacaram algumas características dos sertanejos a partir da obra de Luiz Gonzaga, refletindo um registro sociohistórico das nuanças desse povo nos meados dos anos 1940 a 1980, o que ainda é pouco relatado na literatura. (Sousa, 2017)

Ao analisar os dados referentes às características do trabalhador sertanejo nas canções de Gonzaga, notou-se que um conjunto de características pessoais e regionais influenciavam as decisões desses trabalhadores, dentre as quais estavam a escassez e a subvalorização do trabalho (Ab'Sáber, 1999). Desde a década de 1970 , com o desenvolvimento do capitalismo no campo e a reestruturação produtiva do capital, ocorreram algumas mudanças na relação entre o trabalhador e o meio rural, que culminaram em falta de trabalho e/ ou na exploração do trabalhador sertanejo. Tais mudanças intensificaram ainda mais a emergência de novas estratégias para a obtenção de renda por parte de trabalhadores rurais, motivando-os a migrar em busca de melhores condições (Albuquerque, 2002). Noutras palavras, embora a migração seja anterior à década de 1970, pode-se dizer que a partir desse período ela começou a ser mais comum para os trabalhadores sertanejos.

A migração foi uma das formas para amenizar o forte impacto do capitalismo no campo e da exploração do trabalhador sertanejo. Porém, houve aqueles que tentaram lidar com as dificuldades e permaneceram no sertão, sobrevivendo da melhor forma possível e submetendo-se à informalidade do trabalho, ou ainda, a condições de trabalho análogas à escravidão, fatores esses que precarizaram ainda mais a vida dessas pessoas (Ab'Sáber, 1999; Baptista, 2013; G. Rocha \& Brandão, 2013).

A expectativa de melhorar de vida motiva a migração, a busca por trabalho e a volta para casa. Tais conteúdos estão intimamente relacionados às características de trabalho no sertão, o que foi trazido à pauta nas classes deste estudo. Essas formas de se adaptar às dificuldades, como a migração e o retorno para casa, podem estar enredadas, ainda, com as expectativas de que há alguém, além de Deus, olhando pela região, prometendo trabalho e esperança para a sobrevivência desse trabalhador e de sua família, conforme pode ser observado abaixo:

Meu Nordeste começou a melhorar, os homem grande tão olhando pro norte, talvez agora o sertanejo tenha sorte. Coragem gente! Não vamos desanimar. Pega na enxada, que a coisa vai melhorar. Dizem que os banco do governo têm dinheiro, é um tá de fomento pra acabar com o paradeiro, se assim é vamos todos cooperar, quem trabalhar Deus ajuda e ele vai nos ajudar. (Canção: Cantei, 1970)

O trabalho do sertanejo é caracterizado nas canções de Gonzaga como sofrido e desgastante, contudo, é o meio disponível para adquirir bens materiais e garantir a sobrevivência das famílias. De qualquer modo, embora se note o sofrimento em alguns trabaIhadores do campo, é preciso relativizar essa noção, já que também há alguns aspectos positivos nesse tipo de trabalho, tais como a íntima relação com a terra e elementos da natureza que contribuem para processos identitários e de apego para com a sua origem. Com isso, vale ressaltar que não apenas os fatores negativos, mas também os positivos, influenciam diretamente na saúde física e mental dos trabalhadores (Albuquerque, 2002). Sabendo-se que o contexto no qual estavam e continuam inseridos trabalhadores sertanejos é fonte de desadaptação, é deveras esperado que esses

Estudos de Psicologia, 23(1), janeiro a março de 2018, 22-32 
trabalhadores se vinculem a algo em busca de soluções, a exemplo da fé em um trabalho melhor, na chuva, em Deus ou em seus governantes, numa tentativa de lidar com as adversidades enfrentadas cotidianamente.

Enfim, com a análise de conteúdo da presente classe, foi possível ressaltar que, ao passo que os sertanejos passam por adversidades, também criam mecanismos para lidar com essa situação. As características do trabalho no sertão podem ser vistas como desencadeadoras de aspectos específicos de sofrimento, mas também há fatores psicológicos e sociais que auxiliam os trabalhadores a lidarem com as dificuldades e a elas tentarem se adaptar, consoante às virtudes e limitações do contexto no qual estavam inseridos.

\section{Migração (27,9\%)}

A análise das canções revelou que o tema central desta categoria se refere à motivação de trabalhadores sertanejos para migrar em busca de trabalho. Observou-se que a saída do Nordeste, em especial do sertão, acena com a expectativa de melhorar de vida. Entretanto, tem-se como consequência a geração de poderosos estressores sobre a vida desses sujeitos, visto que muitos vão embora e deixam família e amigos, passando a conviver numa cidade desconhecida, exigindo alguma adaptação diante daquela nova condição. Esta classe revelou a migração como dificuldade quando da busca por melhoria de vida. Os termos mais associados nesta classe foram: "homem", "chorar", "irmão", "precisar", "sonho", "vida", "fole", "sua" e "mãe". Dessa forma, propõe-se o seguinte discurso como representativo desta classe: "Quando um homem precisa deixar sua terra ele chora, pois deixa seus familiares para ir em busca de um sonho: uma vida melhor".

A migração é um tema recorrente nos estudos sobre mercado de trabalho que buscam conhecer o perfil daqueles que migram em busca de trabalho (formal ou não) e melhor qualidade de vida. Para Dustmann e Glitz (2011), um indivíduo pode migrar por dois motivos: (a) quando é forçado, seja por causas religiosas e/ ou políticas; e (b) quando ele acredita que as perspectivas econômicas são mais favoráveis em outra região do país. Há décadas o Nordeste aparece nacionalmente como a região de origem de muitos migrantes, principalmente das zonas com longos períodos de seca. Dessa forma, o meio de sobreviver considerado mais viável passou a ser a busca por para regiões economicamente mais abundantes (Ojima \& Fusco, 2016).

Ao analisar as canções de Luiz Gonzaga, foi possível observar traços culturais dos migrantes, identificando linguagens e manifestações que desvendam suas características e significados, revelando aspectos identitários do sertanejo (Oliveira Filho, 2016). Ser nordestino, particularmente sertanejo, nem sempre significou a mesma coisa. Ao longo do tempo, ao passo que foi se criando a identidade desse grupo, ela foi sendo atrelada à miséria, seca, religiosidade, enfim, aspectos comumente ilustrados em canções e demais formas de literatura. Observe-se, então, o seguinte trecho da canção Paraíba, de Luiz Gonzaga:

Quando a lama virou pedra e Mandacaru secou, quando o ribação de sede bateu asa e voou, foi aí que eu vim me embora carregando a minha dor. Hoje eu mando um abraço pra ti pequenina Paraíba masculina, muié macho, sim sinhô. (Canção: Paraíba, 1952)

É possível abstrair que apenas esse curto trecho revela mais sobre população do que está explícito em suas linhas. Implicitamente podem ser apreendidos aspectos culturais e identitários de nordestinos, tais como o saudosismo e admiração pela terra e povo que Ihe viu crescer. Assim, ao se compreender o sutil contexto e suas manifestações próprias de linguagem, são passíveis de interpretação algumas características coletivas; neste caso, dos trabalhadores sertanejos. Esse trecho, narrando a partida causada pela seca, traz a migração enquanto recurso adaptativo, mesmo quando forçosa e temporária.

Neste trabalho, conhecer a percepção da migração a partir de um olhar específico se mostrou de alta significância, visto que foram capturadas as representações do povo sertanejo na voz de um representante um orador - dessa população. Gonzaga parece se apropriar de um discurso de expulsão, incentivada pela seca, mostrando o homem desvalido em seu lugar de origem, pressionado a evadir-se. Esse ponto parece evidente no seguinte trecho:

Por farta d'água perdi meu gado, morreu de sede meu alazão. Inté mesmo a asa branca bateu asas do sertão, entonce eu disse, adeus Rosinha, guarda contigo meu coração (Canção: Asa Branca, 1952).

É visível que as virtudes e limitações da vida no sertão, bem como o sofrimento com a lida da terra, geralmente, são ressaltadas em suas canções, ao mesmo tempo em que se apresentam atrativos do lugar onde se busca melhores condições de vida e maiores chances de obter um trabalho. Assim, ressaltar as qualidades do lugar de destino pode amenizar o sofrimento por estar distante de sua terra e das pessoas que ficaram nela. 
Eu sou do Norte, rumei para São Paulo, fui mudar de sorte com o fole na mão. Comí de tudo, comida italiana, bife parmegiana. (Canção: Cana só de Pernambuco, 1954).

Vou me embora desta terra pra melhorar minha sorte. Um dia eu voltarei, aí a Ingazeira do Norte. Creuza, espere por mim. (Canção: Creuza Morena, 1961)

Os cantos sobre a migração, portanto, transitam entre o incentivar a saída para que se possam alcançar os objetivos pretendidos e a estereotipização do lugar de chegada, sendo frequente a sua desvalorização em relação ao local de origem, para que assim faça mais sentido a supervalorização do ansiado retorno. Essas ideias reforçam a migração como um fenômeno necessário, mas temporário, indicando um percurso a ser trilhado por outras cidades e marcado pelo desejo de retorno à terra de origem (Pereira \& Ribeiro, 2014). Com isso, nas canções a migração pode ser entendida como um meio para um fim, sendo que passar por situações difíceis é algo esperado, pois isso faz parte do enfrentamento das adversidades e da adaptação à nova realidade.

Por fim, entendeu-se que a migração pode ser desadaptativa para quem migra e para quem fica, mas também para o governo local, já que começam a perder mão de obra, acentuando, muitas vezes, a exploração dos trabalhadores que ficaram no sertão. Não se pode, contanto, afirmar que o processo migratório continua sendo o mesmo desde o início da carreira de Luiz Gonzaga até os dias atuais, ainda que permaneçam características semelhantes ao longo desse tempo. Vê-se isso ao comparar os fatores de motivação de migração nas canções de Gonzaga e em trabalhos atuais sobre aspectos psicossociais do fenômeno migratório (ver Coelho \& Trentin, 2014 e Oliveira \& Jannuzzi, 2005).

\section{Desejo de Retorno à Terra (22,9\%)}

O tema central desta classe revelou o desejo de muitos migrantes de voltar para casa e viver no sertão. Abarcaram-se aqui conteúdos relativos ao desejo de retorno como estratégia para lidar com os desafios causados pela saída de sua terra. Alguns termos mais recorrentes nesta classe foram: "boi", "saudade", "deixar", "vaca", "querer", "pra", "muié", "inté" e "voltar". Propôs-se, então, a seguinte sentença simbólica: "Ao deixar minha terra deixei também um pedaço de mim e da minha vida. Disse inté a meu boi, minha vaca e minha muié, e hoje só quero voltar pra casa e deixar essa saudade pra trás".

Como visto anteriormente, o Nordeste - em especial o sertão nordestino - é conhecido por ser a região responsável pela maior taxa de migração. O migrante, ao se deslocar para outra cidade ou região, encontra-se num espaço contraditório quanto ao que acontecerá a si e aos que o acompanham. O motivo da saída é, em geral, de ordem econômica (Ojima \& Nascimento, 2015), isto quer dizer que os indivíduos vão em busca de melhores oportunidades de emprego, como é o caso dos trabalhadores sertanejos em longos períodos de seca na região. Esses trabalhadores partem, em sua maioria, com a sensação de que a situação é provisória, o que facilita sobreviver longe de sua cultura, de suas crenças, enfim, de tudo que lhe é familiar, mas que agora está afastado (Queiroz, 2015).

Pensar na possibilidade de seu retorno, mesmo que distante, permite assegurar-se como indivíduo num lugar diferente. Assim, na migração dois caminhos se revelam primariamente para aqueles que partem: ou retorna a sua origem, ou se fixa definitivamente no local de migração. Há, certamente, quem consiga se inserir quase que completamente no local para o qual migrou ou mesmo estabelecer planos que entrelacem as duas perspectivas, fugindo dessa suposição paradoxal inicial. Entretanto, as canções de Luiz Gonzaga sugerem que o que os sertanejos desejam verdadeiramente é o retorno para casa e o reencontro com o que foi deixado para trás.

Oi mano, a saudade é de mata. Adeus Pernambuco! Tou maluco pra volta, deixei lá na porta da minha choupana com os óio vermêio, com beijo na boca minha pernambucana. (Canção: Adeus Pernambuco, 1952)

Nos trabalhadores sertanejos que migram ou migraram pode surgir o desejo de retorno para sua terra ou o desejo de permanência real e efetiva no local de destino (Baptista, 2013). Não é incomum a intenção de retorno no migrante, visto que ele está se inserindo em um contexto muitas vezes diferente do que está acostumado (Ojima \& Nascimento, 2015; Sayad, 2000). Isso pode remeter, ainda, ao sentimento do migrante no século passado, período de sucesso das canções de Gonzaga. Sobre isso, Martins (1986) comentou que o migrante não se sente em casa quando migra, e, por mais demorada que seja esta sua migração, o anseio da volta estará sempre fazendo companhia.

Lá no meu pé de serra deixei ficar meu coração. Ai, que saudades tenho, eu vou voltar pro meu sertão. No meu roçado trabalhava todo dia, mas no meu rancho tinha tudo o que queria. (Canção: No meu pé de serra, 1947)

Enfim, de uma maneira geral, ao analisar essa classe talvez se possa dizer que o retorno (ou seu desejo) não ocorre simplesmente pelo sucesso ou fracasso econômico dos sertanejos no mercado de trabalho de destino. Ele também ocorre por questões

Estudos de Psicologia, 23(1), janeiro a março de 2018, 22-32 
afetivas ligadas a amigos, família e ao local de origem, por um desenvolvimento econômico e ou da qualidade de vida alcançada por esse lugar (Baptista, 2013). São, com isso, fatores muitas vezes multifacetados, abstratos e até incompreensíveis ao olhar alheio, mas que alimentam a esperança de retorno à terra.

\section{Proteção Divina $(20,1 \%)$}

Esta classe revelou a fé em algo maior e a proteção divina como mecanismos de proteção, ou seja, formas de enfrentar situações desencadeadoras de sofrimento. Com isso, foram reunidos conteúdos relativos à fé e religiosidade no papel de mecanismos de enfrentamento, possibilitando uma mais favorável adaptação de trabaIhadores sertanejos. Alguns dos termos mais recorrentes foram: "Deus", "já", "pobre", "famía", "terra", "outro", "morrer", "chegar" e "triste". Para esta classe foi proposta a seguinte sentença como discurso simbólico: "Que Deus ajude essa pobre famía a não morrer de fome como outros morreram, e que possa chegar água na terra que já está seca há tanto tempo, deixando seus filhos tristes".

Dados do Instituto Brasileiro de Geografia e Estatística [IBGE] (2012) indicaram que o sertão nordestino tinha aproximadamente 22 milhões de pessoas no Censo de 2010. Parte dessa população, ao que se constata na literatura, expressa manifestações de fé numa proteção divina, o que conforma traços marcantes da identidade sertaneja (Neri, 2011). Pontes (2014) narra que os sertanejos costumam associar mitos católicos, como o da terra onde corre leite e mel, em contraposição com o semiárido seco e estéril que necessita de um Deus clemente que o leve a esse fim, sendo o sertão o caminho para a tão desejada vida pródiga. Tais manifestações podem então ser observadas em obras musicais, literaturas, relatos, entrevistas a meios de comunicação, sejam eles mais recentes ou não.

Os problemas que acometem o sertão, tais como a seca e a migração por ela motivada, reafirmam a experiência de vida sofrida e podem ajudar na elaboração de uma religiosidade que se associa às características rurais do sertanejo, principalmente daqueles que dependem da fertilidade da terra e da chuva para sobreviver (Fernandes, 2008). Nota-se, então, a importância de fatores socioambientais e culturais nas crenças de uma vida melhor, cujo traçado é determinado por um ser onipotente e sempre presente: Deus.

$\mathrm{Ai}$, ai, eu vou me embora, vou cuidar da prantação, a seca fez eu desertar da minha terra, mas felizmente Deus agora se alembrou de mandar chuva pr'esse sertão sofredor. Sertão das muié séria, dos homes trabaiador. (Canção: A volta da asa branca, 1950)
Em quase todas as culturas é possível observar a ideia de um mundo sobrenatural, onde existe um céu que é comandado por um Deus, Senhor e Soberano, que tem poder sobre tudo e ciência absoluta do que ocorre no mundo terreno. Em outra faceta da questão, o que alimenta a presença cotidiana desse mundo divino na vida das pessoas são as constantes orações, oferendas, promessas, súplicas e devoção que buscam atenuar a ira ou insatisfação de seres celestiais (anjos, deuses, santos), ao mesmo tempo em que geram dádivas, proteção e bênçãos (Armstrong, 2011).

A fé dos trabalhadores sertanejos, ilustrada no cancioneiro de Luiz Gonzaga, reúne atributos de um sistema religioso cristão, dando indícios de uma religiosidade mais popular, tradicional, como algumas vezes já foi classificada por estudiosos que se debruçaram sobre a religiosidade nordestina (Gama, 2012; Pontes, 2014). Isso quer dizer que embora não haja referência à determinada religião, a fé e a religiosidade estavam presentes nas canções de Gonzaga, mesmo que não houvesse a menção física exata a um espaço ou instituição onde esses trabaIhadores pudessem exaltar a um Deus. Era essa fé que os ajudava a enfrentar as adversidades que surgiam ao longo de suas vidas, enquanto pessoas e trabalhadores.

Meu São Pedro me ajude, mande chuva, chuva boa, chuvisquinho, chuvisqueiro, nem que seja uma garoa. Uma vez choveu na terra seca, sabiá então cantou, houve lá tanta da fartura que o retirante voltou. Tava lá eu na pisada Tum, tum, tum Oi! Graças a Deus Choveu garoou. (Canção: Baião na garoa, 1952)

No contexto do sertão nordestino, usar a fé como estratégia para enfrentar as adversidades parece surgir com a função de minimizar emoções negativas, o próprio sofrimento, dando esperança aos sertanejos de que tudo vai se resolver (um dia), o que ajuda a acalmá-los perante as dificuldades. Essa estratégia pode promover, ainda, distração, já que a confiança em um Deus que tudo pode, ameniza parte de suas preocupações. Portanto, é possível dizer que a fé pode contribuir positivamente para o enfrentamento das adversidades presentes no local de trabalho ou no lar, pois quanto maior for sua fé, maior poderá ser a chance de se adaptarem positivamente ao longo da vida.

\section{Síntese das Classes: Modos de Enfrentamento em Trabalhadores Sertanejos na Obra de Luiz Gonzaga}

A análise das classes permitiu conhecer aspectos relativos ao trabalho no sertão, bem como estratégias criadas para lidar com as adversidades decorrentes da experiência de viver nesse local. Todas as classes abarcaram, 
ao menos em parte, eventos desencadeadores de sofrimento e possíveis estratégias para lidar com tais eventos, tais como a fé na proteção divina e esperança de um dia retornar para a região de origem e ser feliz.

É ainda possível observar que Gonzaga instituiu em suas canções o Nordeste como espaço de saudade, de tradições, de homens simples, trabalhadores e tementes a Deus. Observou-se, por exemplo, que a fé, religiosidade e/ou esperança estão presentes na vida dos trabalhadores sertanejos, que precisavam se apegar a uma fonte poderosa para atenuar os problemas enfrentados no dia a dia. Constatou-se também que essa fé está ligada a características do trabalho no sertão da época, a qual demonstra ser fator de proteção diante das dificuldades encontradas devido à seca, como baixa renda e excesso de sofrimento no trabalho. A esperança de melhoria nas condições de trabalho e a vida a ele atrelada também sugeriram estarem presentes no papel de estratégias que os ajudam a lidar com as dificuldades.

A migração, que é um objeto de estudo usual nas ciências agrárias e humanas, é também relevante na Psicologia por exercer marcante impacto na vida de todos aqueles envolvidos nesse fenômeno, cuja repercussão negativa tende a ser mais poderosa quando isso ocorre de modo forçoso em virtude da quase impossibilidade de sobrevivência em sua terra de origem. Noutras palavras, o estudo da capacidade de adaptação se revelou como um pano de fundo importante para o entendimento dos efeitos individuais e coletivos do processo migratório, o que justificou e incentiva a continuidade do olhar a partir da Psicologia.

De forma geral, as classes léxicas aqui detectadas trouxeram o Nordeste como um lugar que engendra diferentes facetas para o sertão e seu povo: há aqueles sertanejos valentes, do tipo "cabra macho da peste", e também aqueles sertanejos sofridos, quebrantados pela seca e pela fome. Ambos parecem ser presentes e não necessariamente excludentes na obra de Luiz Gonzaga, surgindo como reflexos da qualidade da adaptação às adversidades impostas pelo seu meio e consequentes experiências de vida. Ademais, a pluralidade de contextos e palavras das canções que retratam o sertanejo como trabalhador chamaram atenção para a influência da cultura nas formas de lidar com problemas se adaptar a eles. Notou-se, assim, que a migração e a caracterização do trabalho no sertão se destacaram como desafios, enquanto que a fé em um Ser divino foi uma das principais fontes de conforto e esperança para o que há de vir.
Os temas das canções então analisadas se concentraram em problemas dos sertanejos, narrando detalhes da vida cotidiana. Elas falavam do trabalho de vaqueiros e roceiros, de pessoas comuns e suas orações, ao drama do trabalhador sertanejo sofrendo pela seca da terra e de sua triste partida para outra cidade. Com efeito, não é apenas o ritmo e a letra que impactam na escuta e produzem admiração pelas canções de Luiz Gonzaga. Suas expressões regionalizadas e os elementos culturais nordestinos ficam patentes na transmissão de mensagem específicas a respeito da vida do trabaIhador sertanejo. Todos esses elementos ainda permitiram significar culturalmente o Nordeste, tornando-o fonte de conhecimento para a Psicologia.

\section{Considerações finais}

O presente trabalho buscou conhecer as características dos trabalhadores sertanejos e suas formas de lidar com as adversidades, segundo dados extraídos de canções de Luiz Gonzaga. Traçou-se então uma narrativa do sertão baseado no espaço e obra desse cantor, abordando seu reflexo sociohistórico, bem como aproximações com os tempos atuais. Com isso, parte de sua arte musical foi avaliada como dimensão psicossocial e cultural presente na representação construída de um povo: trabalhadores sertanejos. O sertão cantado por Gonzaga recria, assim, uma possibilidade de conhecimento de dinâmicas individuais e coletivas a partir de um ponto de vista da Psicologia.

A despeito de suas possíveis contribuições, este trabalho possui limitações. Acredita-se que principal delas está ligada à temporalidade musical, uma vez que o período de atividade de Luiz Gonzaga terminou em meados de 1989. Por tal razão, é necessário entender que as análises e inferências a respeito das dificuldades vivenciadas pelo povo nordestino são mais claramente ligadas a um contexto de época específico. Logo, talvez as conclusões então obtidas não reflitam apropriadamente o panorama atual da migração, seca ou realidade do trabalhador nordestino. Além disso, a letra de uma música não está desassociada da melodia, do ritmo e do estilo, sendo necessário, na medida do possível, considerar todo o cenário na análise.

De modo similar, faz-se pertinente ressaltar que a expressão da vida nordestina produzida por Luiz Gonzaga foi um marco na sua carreira também por encontrar no Rio de Janeiro um "nicho de mercado" que interessou às gravadoras e impulsionou a produção de

Estudos de Psicologia, 23(1), janeiro a março de 2018, 22-32 
mais músicas dentro da temática (Costa, 2012). Assim, isso revela que além dos elementos musicais, há balizamentos sociais e econômicos que devem ser levados em consideração ao se analisar as canções cantadas e interpretadas por Luiz Gonzaga. De qualquer modo, cabe aconselhar que futuras pesquisas também levem em consideração o contexto em que tais canções foram escritas, buscando assim entender questões socioeconômicas que podem ser apreendidas por detrás de um cancioneiro, a exemplo do que se viu na obra de Luiz Gonzaga e aqui se tentou analisar, ainda que não tenha sido um objetivo inicialmente proposto.

O estudo do povo sertanejo ilustrado em obras musicais suscita uma análise de como uma cultura influencia relações do indivíduo com o seu meio, ajudando a forjar perfis individuais e coletivos de enfrentamento do sofrimento em comum. Ademais, como dito por Sousa (2017), as músicas transmitem memórias para futuras gerações, fazendo com que os indivíduos desenvolvam um sentimento de pertença em relação a uma dada cultura regional. Por isso, reforça-se aqui que a música pode ser uma fonte de captura da realidade pela Psicologia, visto favorecer ao entendimento de como pessoas e grupos se desenvolvem em meio às adversidades.

\section{Referências}

Ab'Sáber, A. N. (1999). Sertões e sertanejos: uma geografia humana sofrida. Estudos Avançados, 13(36), 7-59. doi: 10.1590/ S0103-40141999000200002

Albuquerque, F. J. B. D. (2002). Psicologia social e formas de vida rural no Brasil. Psicologia: Teoria e Pesquisa, 18(1), 37-42. doi: 10.1590/ S0102-37722002000100005

Armstrong, K. (2011). Em defesa de Deus: o que a religião realmente significa. São Paulo: Companhia das letras.

Baptista, E. A. (2013). Aspectos teóricos sobre migração de retorno no Brasil. Revista Geografias, 9(2), 8-20. Recuperado de http://www.igc. ufmg.br/portaldeperiodicos/index.php/geografias/article/view/589

Bendassolli, P. F., \& Gondim, S. M. G. (2013). Significados, sentidos e função psicológica do trabalho: discutindo essa tríade conceitual e seus desafios metodológicos. Avances en Psicología Latinoamericana, 32(1), 131-147. doi: 10.12804/apl32.1.2014.09

Brilhante, A. V. M., Silva, J. G., Vieira, L. J. E. D. S., Barros, N. F D., \& Catrib, A. M. F. (2017). Construção do estereótipo do "macho nordestino" nas letras de forró no Nordeste brasileiro. Interface-Comunicação, Saúde, Educação, 22(64), 13-28. doi: 10.1590/1807-57622016.0286

Camargo, B. V. (2005). ALCESTE: um programa informático de análise quantitativa de dados textuais. In A. S. P. Moreira, B. V. Camargo, J. C. Jesuíno, \& S. M. Nóbrega (Orgs.), Perspectivas teórico-metodológicas em representações sociais (pp. 511-539). João Pessoa: Editora da UFPB.
Camargo, B. V., \& Justo, A. M. (2013). Tutorial para uso do software de análise textual IRAMUTEQ. Recuperado de http://www.iramuteq org/documentation/fichiers/tutoriel-en-portugais

Coelho, G. P., \& Trentin, R. C. (2014). Nordeste pra frente: retratos do povo na voz de Luiz Gonzaga. In Círculo Fluminense de Estudos Filológicos e Linguísticos (Org.), XVII Congresso Nacional de Linguística e Filologia. Cadernos do CNLF (Vol. XVIII, n. 01, pp. 601 614). Recuperado de http://www.filologia.org.br/xviii_cnlf/cnlf/01/ Cad_CNLF_XVIII_01_analise.pdf

Cordeiro, B. S. (2008). As canções de Luiz Gonzaga sob o olhar da análise crítica do discurso (ACD). (Dissertação de Mestrado). Recuperado de http://tede2.unicap.br:8080/handle/tede/681

Costa, J. H. (2012). Luiz Gonzaga: entre o mito da pureza musical e a indústria cultural. Revista Espaço Acadêmico, 11(130), 135146. Recuperado de http://periodicos.uem.br/ojs/index.php/ EspacoAcademico/article/view/14450/8836

Dustmann, C., \& Glitz, A. (2011). Migration and education. In E. A. Hanushek, S. Machin, \& L. Woessmann (Orgs.), Handbook of the economics of education (pp. 327-439). North Holland: Elsevier.

Faro, A., \& Pereira, M. E. (2013). Estresse: revisão narrativa da evolução conceitual, perspectivas teóricas e metodológicas. Psicologia, Saúde \& Doenças, 14(1), 78-100. Recuperado de http://www.scielo.mec.pt/scielo.php?script=sci_arttext\&pi$\mathrm{d}=$ S1645-00862013000100006\&lng=pt\&tIng=pt

Fernandes, G. V. (2008). "Reterritorialização" da cultura sertaneja em Luiz Gonzaga. Cadernos de Cultura e Ciência, 3(1), 1-15. Recuperado de http://periodicos.urca.br/ojs/index.php/cadernos/ article/view/147

Folkman, S. (2011). Stress, health, and coping overview. In S. Folkman (Org.), The Oxford handbook of stress, health, and coping (pp. 3-11). Nova lorque: Oxford University Press.

Freire, L. S. (2010). Forró e indústria fonográfica: memória e o uso das estratégias midiáticas. Trabalho apresentado no II Musicom Encontro de Pesquisadores em

Comunicação e Música Popular, São Luís, Maranhão. Recuperado de http://musica.ufma.br/musicom/trab/2010_GT3_01.pdf

Gama, V. B. (2012). “Louvado seja!": representações do sagrado nas canções de Luiz Gonzaga. (Dissertação de Mestrado). Recuperado de http://repositorio.unb.br/handle/10482/11573

Instituto Brasileiro de Geografia e Estatística - IBGE. (2012). Instituto Nacional do Semiárido - INSA. Sinopse do Censo Demográfico para o Semiárido Brasileiro. Campina Grande: INSA.

Martins, J. S. (1986). Não há terra para plantar neste verão. Petrópolis: Vozes.

Moraes, A. C. R. (2009). O sertão: um "outro" geográfico. Revista da Rede Brasileira de História da Geografia e Geografia Histórica, 4(1), 87-101.

Neri, M. C. (2011). Novo mapa das religiões. Rio de Janeiro: Fundação Getúlio Vargas.

Ojima, R., \& Fusco, W. (2016). Migração no semiárido setentrional: dinâmica recente, retorno e políticas sociais. In Grupo de Trabalho de Migração da Associação Brasileira de Estudos Populacionais (Org.), IX Encontro Nacional Sobre Migrações (Vol. 2, n. 2, pp. 259-276). Recuperado de http://pdf.blucher.com.br.s3-sa-east-1. amazonaws.com/socialsciencesproceedings/ix-gtmigra/ST5-2.pdf 2(2), 259-276

Ojima, R., \& Nascimento, T. C. L. (2015). Nos caminhos para o nordeste: reflexões sobre os impactos diretos e indiretos da migração 
de retorno no período recente. Redes, 20(3), 48-62. doi: 10.17058/ redes.v20i3.4526

Oliveira, K. F. D., \& Jannuzzi, P. D. M. (2005). Motivos para migração no Brasil e retorno ao Nordeste: padrões etários, por sexo e origem/ destino. São Paulo em Perspectiva, 19(4), 134-143. doi: 10.1590/ S0102-88392005000400009

Oliveira Filho, P. (2016). Discurso e identidade: a pobreza e a miséria nordestina em relatos de jornais paraibanos e pernambucanos. In M. E. O. Lima, A. R. R. Torres, \& E. M. Techio (Orgs.), Identidade nacional e representações do Brasil: abordagens integrativas (pp. 149-176). São Paulo: Scortecci.

Pereira, V. G., \& Ribeiro, E. M. (2014). Novos padrões de migração entre agricultores familiares reassentados do Alto Jequitinhonha, MG. Organizações Rurais \& Agroindustriais, 16(1), 1-34. Recuperado de http://repositorio.ufla.br/jspui/handle/1/8984

Pontes, E. T. M. (2014). Fé e pragmatismo no sertão. Mercator, 13(2), 155-168. doi: 10.4215/RM2014.1302.0011

Queiroz, S. N. (2015). Tendências das migrações interestaduais de retorno no Brasil. Ciência e Sustentabilidade, 1(1), 77-95. Recuperado de https://periodicos.ufca.edu.br/ojs/index.php/ cienciasustentabilidade/article/view/22/Artigo\%206

Rocha, I. G. V. (2013). A identidade cultural nordestina na música de Luiz Gonzaga a partir dos níveis fonéticos. Revista Desenredos, 5(19), 1-29. Recuperado de http://desenredos.dominiotemporario. com/doc/19-Artigo-LuizGonzaga-Italo.pdf

Rocha, G., \& Brandão, A. (2013). Trabalho escravo contemporâneo no Brasil na perspectiva da atuação dos movimentos sociais. Revista Katálysis, 16(2), 196-204. doi: 10.1590/ S1414-49802013000200005

Santos, C. O. (2012). Forró x forró: discursos, polarizações e diversidade num campo musical. In Universidade Federal do Rio de Janeiro UniRio(Org.), Anais do II Simpom 2012 - Simpósio Brasileiro de Pós-graduandos em música (pp. 676-686). Rio de Janeiro, RJ.
Recuperado de http://www.batuquebook.com.br/wp-content/ uploads/2014/11/Artigo_ForroxForro_Climerio_de_Oliveira.pdf

Santos, J. F. (2004). Luiz Gonzaga: a música como expressão do Nordeste. São Paulo: Ibrasa.

Santos, R. A. (2013). Contextualizando o espaço: ideias e artifícios na construção da imagem de Nordeste (1920-1940). Revista Eletrônica Discente História, 1(1), 1-14. Recuperado de https:// www3.ufrb.edu.br/seer/index.php/historiacom/article/view/18

Sayad, A. A. (2000). O retorno: elemento constitutivo da condição do migrante. Revista Travessia, 13(Número Especial), 7-32.

Silva, J. R., \& Jesus, P. (2012). Senhores das cercas e das secas: algumas considerações a respeito da concentração da terra e da água no nordeste brasileiro. EDUCTE: Revista Científica do Instituto Federal de Alagoas, 3(2), 1-18. Recuperado de http://www.kentron. ifal.edu.br/index.php/educte/article/view/85

Silva, U. M. (1997). Luiz Gonzaga: discografia do rei do baião. Salvador: BDA.

Sobral, M. R. B. (2015). Luiz Gonzaga e alimentação sertaneja: as práticas alimentares representadas nas letras musicais. Interações, 16(1), 155-162. doi: 10.1590/1518-70122015113

Sousa, S. L. (2017). A canção "vozes da seca" de Luiz Gonzaga: vozes de protesto sob uma perspectiva da análise do discurso. Revista do GELNE, 19(1), 79-88. Recuperado de https://periodicos.ufrn.br/ gelne/article/view/11279/8400

Sousa Camurça, C. E., Alencar, A. B., Cidade, E. C., \& Ximenes, V. M. (2016). Implicações psicossociais da seca na vida de moradores de um município da zona rural do nordeste do Brasil. Avances en Psicología Latinoamericana, 34(1), 117-128. doi: 10.12804/ apl34.1.2016.08

Trotta, F. (2012). Som de cabra macho: sonoridade, nordestinidade e masculinidades no forró. Comunicação, Mídia e Consumo, 9(26), 151-172. doi: 10.18568/cmc.v9i26.349

Geovanna Santana de Souza Turri, Mestre em Psicologia Social pela Universidade Federal de Sergipe (UFS), é Psicóloga Clínica.

Endereço para correspondência: Avenida Hermes Fontes, 36.

Suissa - Aracaju/SE. Telefone para contato: (79)98832-2337.

E-mail: geovannasantana92@gmail.com

André Faro, Doutor em Psicologia pela Universidade Federal da Bahia (UFBA), Pós-Doutorado em Epidemiologia e Saúde Mental pela John Hopkins University, é Professor Adjunto do Departamento e Programa de Pós-Graduação em Psicologia da Universidade Federal de Sergipe (UFS). E-mail: andre.faro.ufs@gmail.com

Marley Rosana Melo de Araújo, Doutorado em Teoria e Pesquisa do Comportamento pela Universidade Federal do Pará (UFPA), Pós-Doutorado em Psicologia Social pela Universidade Federal da Paraíba (UFPB), é Professora Associada do Departamento de Psicologia da Universidade Federal de Sergipe (UFS). E-mail: marleymeloaraujo@gmail.com

Recebido em 07.Mai.16 Revisado em 12.Mar.18 Aceito em 27.Abr.18 